\title{
CAI in three medical training courses: It was effective!
}

\author{
GERARD M. DEIGNAN and ROBERT E. DUNCAN \\ Air Force Human Resources Laboratory, Lowry AFB, Colorado 80230
}

This study suggests that computer-assisted instruction (CAI) can be used effectively to increase student achievement and decrease training time for medical technologists. CAI is shown to be instructionally more effective than lecture or programmed text (PIT) in several medical training courses. CAI results in greater achievement differences at the lower aptitude level than at the middle or high levels. In contrast, CAI students accomplished objectives in significantly less time than lecture or PIT students, with time savings greatest at the high aptitude level.

A field-tested instructional delivery system that has the capability to produce skilled technicians in less time than conventional methods is of prime interest to medical training administrators. Comparative analyses of the differential effectiveness of computer-assisted instruction (CAI), programmed instructional text (PIT), and lecture methods in the medical training literature have been sparse. The present paper reports initial findings of a comparative study to assess the relative effectiveness of these three delivery modes with students of three different aptitude levels.

The major objectives of this study were to compare CAI with lecture and programmed text modes of instruction on dimensions of (1) instructional effectiveness, (2) time savings, (3) attitudinal acceptance, and (4) instructional delivery costs. The first three dimensions are covered in this paper. ${ }^{1}$ Precourse assessment measures identified the characteristics (e.g., aptitude, biographical data, and attitudes) of learners for whom CAI, lecture, and programmed text might be differentially effective for medical tasks in segments of the three medical training courses.

\section{METHOD}

Three medical training courses (medical laboratory, radiology, and dental assistant) provided a range of learner characteristics suitable for generalizing results to students in medical courses of comparable difficulty. The student sample during formative and summative evaluation consisted of 700 male and female trainees assigned to the Air Force School of Health Care Sciences at Sheppard Air Force Base, Texas. The CAI delivery system was the PLATO IV interactive terminal connected to a mainframe at the Center for Education Research Laboratory (CERL), University of Illinois, Champaign-Urbana, Illinois, via telephone line. The programming language used in PLATO is TUTOR, which allows for real-time author editing as well as student data storage and student file management. Instructional materials from each of the courses were developed in a CAI format by onsite subject-matter experts trained in TUTOR. Comparison between CAI and non-CAI delivery (lecture or PIT) was made on identical instructional objectives and criterion measures. Criterion measures included postinstructional measures of achievement, elapsed time to complete instruction, and atti- tudes toward CAI, PIT, and lecture for 100 randomly selected students in each CAI and non-CAI control condition for each course in summative evaluation. Based upon task analyses, selected precourse assessment measures were developed and administered to all students prior to random assignment to CAI, PIT, or lecture conditions. These measures included: (1) the medical version of the Delta Reading Vocabulary Test (Deignan, Note 1), (2) the General Aptitude Index score from the Armed Services Vocational Aptitude Battery (ASVAB), and (3) the memory, visualization, and biographical tests from the Delta Training Aptitude Battery (Deignan, Note 2). Measures were administered prior to course entry to aid CAI authors in the initial development of instructional material appropriate to the target population in each course and to assist summative evaluators in explaining, interpreting, and generalizing comparative performance results. Similarly, to assist in formative evaluation, all CAI students in the three courses were administered an on-line attitude survey which contained Likert-type items with responses ranging from highly unfavorable (5) to highly favorable (1).

Statistical analyses included multiple regression, conducted to predict learner performance, and one-way analy ses of variance to compare criterion performance between CAI and non-CAI conditions. Analyses of variance ( 2 by 3 ) were conducted to investigate treatment (CAI vs. lecture or PIT) and aptitude effects and any interaction between treatment and aptitude that may have existed.

\section{RESULTS}

Table 1 shows the means and standard deviations for achievement and time to complete instruction in the $\mathrm{CAI}$ and non-CAI conditions of the medical lab (lecture) and radiology courses (PIT). CAI students showed significantly greater achievement than lecture students in the medical lab course $[F(1,246)=69.03, p \leqslant .001]$, and significantly greater achievement than PIT students in radiology $[F(1,185)=4.32, p \leqslant .05]$. Initial dental course data showed no statistically significant achievement differences between CAI and lecture, but data gathering is not yet complete.

CAI student mean time to completion was $14 \%$ less $[\mathrm{F}(1,246)=10.42, \mathrm{p}<.001]$ than lecture students and required $12 \%$ less $[\mathrm{F}(1,185)=5.69, \mathrm{p}<.02]$ time than PIT students. 
Table 1

Mean Percentage Achievement and Mean Time (in Minutes) to Complete Instruction

\begin{tabular}{crrrrr}
\hline & \multicolumn{2}{c}{$\begin{array}{c}\text { Percent Achieve- } \\
\text { ment Score }\end{array}$} & \multicolumn{3}{c}{$\begin{array}{c}\text { Time to Complete } \\
\text { Instruction }\end{array}$} \\
\cline { 2 - 3 } \cline { 5 - 6 } Group & Mean & SD & & Mean & SD \\
\hline Radiology & & & & \\
CAI (97) & 84.72 & 8.14 & 240 & 65 \\
PIT (89) & 81.95 & 10.62 & 271 & 106 \\
Medical Lab & & & & \\
CAI (93) & 89.13 & 13.51 & & 469 & 220 \\
Lecture (154) & 74.19 & 13.84 & 540 & 0 \\
\hline
\end{tabular}

A 2 by 3 analysis of variance of achievement scores revealed significant main effects for the CAI-lecture treatment $[F(1,182)=54.51, p \leqslant .001]$ and aptitude $[F(2,182)=5.41, \mathrm{p}<.01]$ in the medical lab course. Aptitude stratification of achievement scores into approximate thirds by low, middle, and high aptitude revealed that $\mathrm{CAI}$ students on the average demonstrated $18 \%$ higher achievement than lecture controls at the low aptitude level. Similar CAI achievement superiority, in comparison to lecture controls, was also reflected at the middle aptitude ( $89 \%$ vs. $76 \%$ ) and high aptitude levels $(92 \%$ vs. $79 \%)$. No statistically significant interactions between aptitude level and CAI-lecture treatment conditions were found. A 2 by 3 analysis of variance of time to complete instruction in the medical lab course revealed a significant main effect for $\mathrm{CAI}$-lecture treatment $[F(1,182)=314.04, p \leqslant .001]$ and aptitude $[F(2,182)=$ $7.35, \mathrm{p} \leqslant .001]$, and a significant $\mathrm{A}$ by $\mathrm{B}$ interaction $F(2,182)=9.07, p \leqslant .001]$. The interaction showed that CAI time savings increased to $33 \%$ at the high aptitude level compared to high aptitude lecture controls in the medical lab course.

For the radiology course, achievement scores showed a statistically significant aptitude main effect $[\mathrm{F}(2,154)$ $=6.27, p \leqslant .01]$ and a significant CAI-PIT Treatment by Aptitude interaction $[F(2,154)=9.23, p \leqslant .001]$. Lowaptitude CAI students demonstrated $7 \%$ higher achievement than low-aptitude PIT students.

Analysis of variance of time to complete instruction in the radiology course revealed a significant main effect for aptitude $[F(2,154)=9.13, p \leqslant .001]$ and a significant CAI-PIT Treatment by Aptitude interaction $[F(2,154)=6.69, p \leqslant .01]$. The low-aptitude CAI students demonstrated $17 \%$ greater time savings than their low-aptitude PIT counterparts.

Multiple stepwise regression analyses prior to summative evaluation between criterion achievement scores and preassessment predictors revealed that reading vocabulary and visualization aptitudes, in addition to biographical items pertaining to male-female differences and need for achievement, comprised the major variables predictive of achievement scores $(R=.63, p \leqslant .01)$ in the medical lab course. Variables predictive of time to conıplete instruction included reading vocabulary, visualization, memory, self-concept, and preference for instruction by computers rather than lectures $(R=.68$, $\mathrm{p}<.01)$. In contrast, radiology course prediction of achievement and time rested primarily upon memory and visualization aptitudes, in addition to biographical items pertaining to male-female differences, self-concept, and level of aspiration $(\mathrm{R}=.66, \mathrm{p}<.01)$. Variables predictive of final dental course performance are currently being determined.

Knowledge of learners' characteristics predictive of subsequent performance during formative evaluation not only provided CAI authors with a better understanding of variables associated with performance, but also suggested instructional strategies and motivational techniques for materials revision. Cross-validation is being conducted on students in the summative evaluation stage in each course to obtain cross-validated regression equations. Preliminary data indicate shrinkage is slight.

Results of the on-line attitude survey revealed that CAI students both within and across courses responded with favorable attitudes $(\mathrm{N}=363)$ toward the CAI medium on the 5-point scale, with 3 as the neutral point.

\section{CONCLUSIONS}

CAI students demonstrated significantly more achievement than PIT and lecture controls; average CAI time to complete instruction was $14 \%$ less than lecture controls and $12 \%$ less than PIT students. CAI achievement and time savings increased at certain aptitude levels to as much as 18 percentage points and $33 \%$ less time than controls.

If time to complete instruction is deemed important, CAI might profitably be allocated to high-aptitude students rather than lecture. However, if the objective is to increase student achievement in a course comparable to the medical laboratory course, $\mathrm{CAl}$ could be employed to significantly increase total average student achievement at all aptitude levels, as indicated by our results. Depending upon type and number of alternative instructional resources available, optimization strategies could be employed to increase both the average achievement of low-aptitude students and increase overall student time savings by allocating CAI to students at the low and high aptitude levels and lecture to midaptitude students.

Course-specific differences, such as course task and criterion difficulty, lock-step vs. self-paced instruction and learner characteristics, such as aptitude, can combine to produce outcomes that require different instructional strategies. Results from the CAI vs. PIT comparison in the radiology course led to the empirically based conclusion of assigning CAI to low-aptitude students to obtain both greater time savings (17\%) and greater achievement $(7 \%)$ at the low aptitude level than 
programmed text. To increase overall instructional achievement and efficiency in a comparable course, CAI may be allocated to low-aptitude students, whereas programmed text is as effective as CAI for higher aptitude students. Assignment of PIT to mid- and highaptitude students appears both reasonable and resourceful.

\section{REFERENCE NOTES}

1. Deignan, G. M. The Delta Reading Vocabulary Test. Unpublished test, 1973. Data reported in Dansereau, D. F. Factors related to developing optimal instructional sequences (II) (Technical Report 73-51). Lowry AFB, Colo: Air Force Human Resources Laboratory. Also reported in Long, G. L. The develop- ment and assessment of a cognitive-based learning strategy training program. Unpublished doctoral dissertation, Texas Christian University, 1976.

2. Deignan, G. M. The Delta Training Aptitude Battery: Reading vocabulary, memory, visualization. attitudinal and biographical measures. Unpublished measures reported in Evaluation plan: Evaluation of Plato IV Air Force medical training. Washington, D.C: Defense Advanced Research Project Agency, 1976.

\section{NOTE}

1. A full report of this project is in preparation as an AFHRL technical report. Publication is anticipated during spring 1978. 